\title{
MENGKAJI KEPUASAN DAN LOYALITAS KONSUMEN SUSU BUBUK TINGGI KALSIUM DENGAN PENDEKATAN MULTI-ATRIBUT
}

\author{
Amam $^{1,2)}$ dan Pradiptya Ayu Harsita ${ }^{2)}$ \\ 1) Dosen Program Studi Agribisnis Fakultas Pertanian Universitas Jember \\ 2) Dosen Program Studi Peternakan Fakultas Pertanian Universitas Jember \\ Email: Amam.faperta@unej.ac.id
}

\begin{abstract}
Constumer satisfaction and loyalty is one indicator of marketing success. This study aimed to analyze the level of customer satisfaction and loyalty milk powder with high calcium by attributes attached to high calcium milk powder products. Milk powder used as the object of the research was Anlene milk powder and Hilo milk powder. Attributes used in the study are: brand, flavour, label, price, and promotion. Determination of the sample using multistage sampling technique. The data analysis used is multiple linear regression. The results showed that milk powder Anlene attributes that affect customer satisfaction is a flavor of $(0,001)$, price $(0,018)$, and promotion $(0,023)$, while milk powder Hilo attributes that affect customer satisfaction is the brand $(0,024)$ and the label $(0,015)$. Anlene milk powder attributes that influence consumer loyalty is priced at 0,017, while the milk powder Hilo attributes that influence consumer loyalty is the brand of 0,021.
\end{abstract}

Keywords: satisfaction, loyalty, customer, attributes.

\section{PENDAHULUAN}

Atribut produk dapat mempengaruhi tingkat kepuasan dan loyalitas konsumen. Atribut merupakan sesuatu yang melekat pada produk dan terdiri dari bentuk visual, audio, dan audio-visual. Rahmawati (2013) atribut produk adalah unsur-unsur produk yang dianggap penting oleh konsumen dan bisa dijadikan dasar dalam pengambilan keputusan pembelian.

Atribut produk dapat menentukan sikap konsumen terhadap suatu produk tertentu. Atribut susu bubuk berkalsium tinggi yang pernah diteliti oleh Amam (2015) terdiri dari atribut merek, rasa, label, harga, dan promosi. Atributatribut tersebut memiliki nilai positif berdasarkan hasil analisis Fishbein yaitu 4,93 pada susu bubuk Hilo dan 4,73 pada susu bubuk Anlene.

Sikap konsumen dipengaruhi oleh atributatribut produk, sehingga akan mempengaruhi keputusan pembelian (Amam dan Pradiptya, 2017). Hasil dari keputusan pembelian ialah kepuasan dan loyalitas konsumen.

Kepuasan konsumen ialah tingkatan perasaan seseorang setelah membandingkan hasil yang dirasakan dengan harapan yang diinginkan (Kottler, 2000), dan loyalitas adalah situasi dimana konsumen menilai dan bersikap positif terhadap suatu produk dan disertai dengan pem- belian ulang secara konsisten (Chasanah, 2010).

Analisis mengenai sikap, kepuasan dan loyalitas konsumen dapat menghasilkan manfaat diagnostik dan prediktif (Sihombing dan Situmorang, 2014). Identifikasi pangsa pasar yang reseptif, mengevaluasi kegiatan pemasaran yang sekarang dan yang potensial, dan meramalkan perilaku masa datang adalah sebagian dari cara-cara utama di mana kesemuanya itu dapat membantu pengambilan keputusan pemasaran (Engel, Blackwell, and Miniard 2001).

Konsumen yang mempunyai tingkat loyalitas tinggi merupakan aset tak ternilai bagi perusahaan. Indikator konsumen yang loyal menurut Chasanah (2010) yaitu melakukan pembelian ulang, melakukan penolakan terhadap produk pesaing, dan memberikan referensi kepada orang lain.

Kepuasan pelanggan terhadap suatu produk akan mempengaruhi loyalitas konsumen (Istiana, Syahlani, dan Nurtini, 2006). Hal tersebut karena kepuasan pelanggan menurut Rangkuti (2002) ialah respon pelanggan terhadap ketidaksesuaian antara tingkat kepentingan sebelumnya dan kinerja aktual yang dirasakan konsumen setelah melakukan pemakaian.

Tujuan dari penelitian ini adalah untuk menganalisis tingkat kepuasan dan loyalitas 
konsumen susu bubuk berkalsium tinggi berdasarkan atribut yang melekat pada produk.

\section{METODE PENELITIAN}

Lokasi penelitian di Kota Malang, mengacu pada pertimbangan bahwa belanja susu oleh masyarakat Kota Malang mencapai Rp 26.000 per keluarga per bulan (BPS, 2014). Waktu pengambilan data dilakukan pada bulan Maret sampai dengan Mei 2015 dan diolah kembali pada tahun 2017. Penelitian menggunakan studi kasus pada konsumen susu bubuk berkalsium tinggi merek Anlene dan Hilo di Kota Malang.

Atribut yang digunakan pada susu Hilo dan Anlene meliputi: merek, rasa, label, harga dan promosi.

1. Merek $\left(X_{1}\right)$ adalah nama, inisial atau kombinasi unsur-unsur tersebut yang dirancang untuk mengidentifikasi suatu produk. Indikatornya adalah terkenal.

2. Rasa $\left(\mathrm{X}_{2}\right)$ adalah kelengkapan rasa yang bisa dinikmati konsumen. Indikatornya adalah enak.

3. Label $\left(\mathrm{X}_{3}\right)$ adalah bagian produk yang membawa informasi verbal tentang produk, misalkan keterangan halal dari MUI, label dari BPOM atau Departemen Kesehatan Republik Indonesia, komposisi bahan, slogan, tanda kadaluarsa (expired). Indikatornya adalah menarik perhatian dan mudah diingat.

4. Harga $\left(\mathrm{X}_{4}\right)$ adalah sejumlah uang yang akan diberikan kepada penjual (produsen) untuk mendapatkan sejumlah barang tertentu sesuai dengan perjanjian antara penjual dan pembeli. Harga merupakan kemampuan daya beli konsumen untuk mendapatkan dan mengkonsumsi susu bubuk berkalsium tinggi. Pengukurannya adalah kemampuan daya beli.

5. Promosi $\left(\mathrm{X}_{5}\right)$ adalah media untuk memperkenalkan suatu produk (barang atau jasa) kepada masyarakat. Bentuk promosi bisa melalui visual, audio dan audio-visual. Indikatornya ialah berkesan dan mengena.

6. Kepuasan $\left(\mathrm{Y}_{1}\right)$ adalah tingkatan perasaan seseorang setelah membandingkan hasil yang dirasakan dengan harapan yang diinginkan. Indikatornya ialah puas dengan produk, harapn terpenuhi, dan tidak kalah dibanding produk sejenis.

7. Loyalitas $\left(\mathrm{Y}_{2}\right)$ adalah situasi dimana konsumen menilai dan bersikap positif terhadap suatu produk dan disertai dengan pembelian ulang secara konsisten. Indikatornya ialah penggantian produk akan selalu merek yang sama, membeli merek yang sama meskipun harga produk lain lebih murah, dan memberikan rekomendasi kepada orang lain.

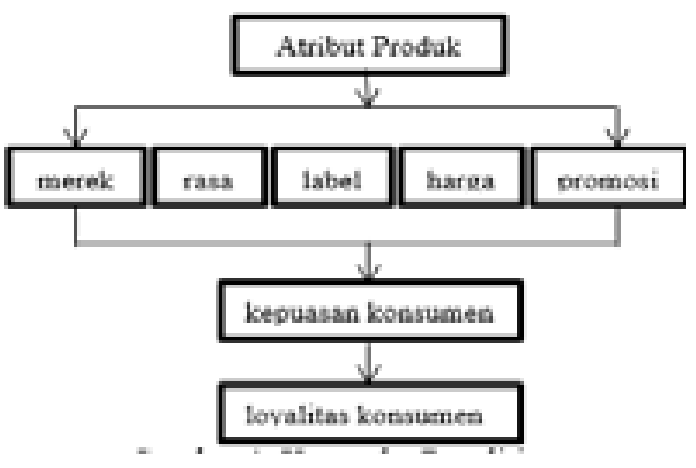

Gambar 1. Kerangka Penelitian

Rumusan masalah dijawab dengan menggunakan analisis regresi linear berganda. Regresi ini didasari pada hubungan fungsional maupun hubungan kausal dari dua atau lebih variabel independen dengan satu variabel dependen (Wiyono, 2011). Analisis regresi ganda dapat dilakukan jika variabel independennya terdapat minimal dua, adapun persamaannya dituliskan sebagai berikut:

$Y=\alpha+\beta_{1} X_{1}+\beta_{2} X_{2}+\beta_{3} X_{3}+\beta_{4} X_{4}+\beta_{5} X_{5}$

Metode yang digunakan ialah multistage sampling, yaitu pemilihan sampel secara bertahap untuk mendapatkan penyebaran populasi sampel secara merata, sehingga diharapkan bisa mewakili keseluruhan. Sampel yang digunakan adalah siswa SMA Negeri di Kota Malang. Berdasarkan teori perhitungan sampel Krejcie-Morgan (Sanusi, 2012), maka didapatkan jumlah sampel sebanyak 80 responden, sehingga masing-masing 40 responden susu Hilo dan 40 responden susu Anlene.

Responden diminta mengisi kuisioner dengan ketentuan:

sangat setuju skor +2

setuju

skor +1

netral

skor 0

tidak setuju skor -1

sangat tidak setuju skor -2

Pembentukan interval kelas dengan rumus:

$=($ skor tertinggi-skor terendah $) /($ jumlah kelas $)$ $=(+2-(-2)) / 5=4 / 5=0,8$

Berdasarkan perhitungan interval kelas, maka didapatkan skor penilaian sebagai berikut:

- skor sangat rendah : $-2 \mathrm{~s} / \mathrm{d}-1,2$ 
- skor rendah

: $-1,19 \mathrm{~s} / \mathrm{d}-0,4$

- skor sedang

: $-0,39 \mathrm{~s} / \mathrm{d} 0,4$

- skor tinggi

: $0,4 \mathrm{~s} / \mathrm{d} 1,2$

- skor sangat tinggi

: $1,21 \mathrm{~s} / \mathrm{d} 2$

\section{HASIL DAN PEMBAHASAN}

\section{Gambaran Umum Penelitian}

Penelitian ini dimaksudkan untuk mengetahui pengaruh atribut terhadap kepuasan dan loyalitas konsumen. Produk yang menjadi obyek penelitian adalah produk susu bubuk berkalsium tinggi merek Hilo dan Anlene dengan atribut harga, kemasan dan merek yang diberi skor +2 , $+1,0,-1$, dan -2 , untuk kategori sangat percaya, percaya, netral, tidak percaya dan sangat tidak percaya.

\section{Profil Produk}

Susu bubuk Hilo diproduksi oleh PT Nutrifood Raya yang berlokasi di Ciawi-Bogor. Susu Hilo merupakan susu yang memiliki label top brand pada tahun 2014. Komposisi pada susu bubuk Hilo terdiri dari skim, gula pasir, maltodekstrin, krimmer nabati, susu bubuk full krim, premix vitamin dan mineral, perisa artificial, vanilla, alga merah, kolin, kromium pikolinat dan perisa karamel.

Susu bubuk Anlene diproduksi oleh PT Tigaraksa Satria, Tbk untuk PT Fonterra Brands yang berlokasi di Jakarta. Komposisi susu Anlene terdiri dari susu bubuk tanpa lemak, maltodekstrin, bubuk whey, susu bubuk, campuran fostrunan-inulin dengan DP minimum 10 , kalsium karbonat, premix mineral dan vitamin $\mathrm{D}$.

\section{Karakteristik Responden}

\section{Jenis Kelamin}

Hasil penelitian menunjukkan bahwa konsumen susu Hilo terdiri dari 29 laki-laki dan 11 perempuan, sedangkan konsumen susu Anlene terdiri dari 17 laki-laki dan 23 perempuan. Hal tersebut menunjukkan bahwa laki-laki lebih memilih produk susu bubuk Hilo dan perempuan lebih memilih produk susu bubuk Anlene.

Tabel 1. Konsumsi Susu Berdasarkan Jenis Kelamin

\begin{tabular}{lcccc}
\hline \multirow{2}{*}{ Jenis Kelamin } & \multicolumn{2}{c}{ Hilo } & \multicolumn{2}{c}{ Anlene } \\
\cline { 2 - 5 } & $\Sigma$ & $\%$ & $\Sigma$ & $\%$ \\
\hline Laki-laki & 29 & 72,5 & 16 & 40 \\
Perempuan & 11 & 27,5 & 24 & 60 \\
\hline \multicolumn{1}{c}{ Jumlah } & 40 & 100 & 40 & 100 \\
\hline
\end{tabular}

Sumber: Data Primer (diolah)
Data dalam Tabel 1 menjelaskan bahwa laki-laki lebih suka mengkonsumsi susu bubuk Hilo, sedangkan perempuan lebih suka mengkonsumsi susu bubuk Anlene. Pertimbangan laki-laki dalam mengkonsumsi susu bubuk Hilo karena atribut label aktifit $(17,5)$, sedangkan pertimbangan perempuan dalam mengkonsumsi susu bubuk Anlene karena manfaat (40\%) dan dorongan orang tua $(5 \%)$.

\section{Perilaku Konsumen}

\section{a. Faktor yang Sering Menjadi Pertimbangan dalam Pembelian Produk}

Terdapat banyak faktor yang dapat melatarbelakangi konsumen dalam memilih jenis produk susu bubuk, dari banyak faktor tersebut terdapat beberapa faktor yang sering menjadi pertimbangan dalam memilih susu bubuk sebagaimana penjelasan di bawah ini:

Tabel 2. Faktor yang Menjadi Pertimbangan Konsumen

\begin{tabular}{lcccc}
\hline Faktor yang Menjadi & \multicolumn{2}{c}{ Hilo } & \multicolumn{2}{c}{ Anlene } \\
\cline { 2 - 5 } $\begin{array}{c}\text { Pertimbangan Kon- } \\
\text { sumen }\end{array}$ & $\Sigma$ & $\%$ & $\Sigma$ & $\%$ \\
\hline Manfaat & 22 & 55 & 16 & 40 \\
Rasa & 7 & 17,5 & 14 & 35 \\
Gaya Hidup & 8 & 20 & 5 & 12,5 \\
Harga & 2 & 5 & 3 & 7,5 \\
Lain-lain & 1 & 2,5 & 2 & 5 \\
\hline \multicolumn{1}{c}{ Jumlah } & 40 & 100 & 40 & 100 \\
\hline Sumber: Data Primer (diolah) & & &
\end{tabular}

\section{b. Tingkat Kepentingan Atribut}

Atribut susu bubuk yang dijadikan pertimbangan dalam penelitian meliputi: 1) merek, 2) rasa, 3) label, 4) harga, dan 5) promosi. Atribut tersebut kemudian dirangking tingkat kepentingannya oleh responden menurut pertimbangannya masing-masing. Perangkingan tersebut dilakukan dengan cara memberi penilaian dari satu sampai lima berdasarkan tingkat kepentingan yang dirasakan oleh responden sebagaimana ditunjukkan dalam tabel di bawah ini: 
Tabel 3. Tingkat Kepentingan Atribut Menurut Konsumen

\begin{tabular}{lcccc}
\hline $\begin{array}{c}\text { Tingkat Kepentin- } \\
\text { gan Atribut } \\
\begin{array}{c}\text { Menurut Kon- } \\
\text { sumen }\end{array}\end{array}$ & $\Sigma$ & $\%$ & $\Sigma$ & $\%$ \\
\hline Harga & 12 & 30 & 20 & 50 \\
Merek & 16 & 40 & 8 & 20 \\
Label & 7 & 17,5 & 6 & 15 \\
Rasa & 2 & 5 & 5 & 12,5 \\
Promosi & 3 & 7,5 & 1 & 2,5 \\
\hline \multicolumn{1}{c}{ Jumlah } & 40 & 100 & 40 & 100 \\
\hline Sumber: Data Primer (diolah) & & &
\end{tabular}

\section{c. Konsumsi Harian}

Konsumsi harian merupakan intensitas kebutuhan atau keinginan pembeli dalam mengkonsumsi susu bubuk berkalsium tinggi tiap harinya. Konsumsi harian dibagi menjadi empat kategori, yaitu 1x/hari, 2x/hari, 3x/hari dan $>3 x /$ hari. Konsumsi harian merupakan salah satu dari perilaku konsumen dalam menghabiskan suatu produk kemudian memutuskan akan melakukan pembelian lagi atau mengganti dengan produk merek lain atau bahkan memutuskan untuk tidak mengkonsumsinya lagi.

Tabel 4. Konsumsi Harian Susu Bubuk Tinggi Kalsium

\begin{tabular}{|c|c|c|c|c|}
\hline \multirow{2}{*}{$\begin{array}{l}\text { Konsumsi } \\
\text { Harian }\end{array}$} & \multicolumn{4}{|c|}{$\begin{array}{c}\text { Merek Susu (Ca } 500 \mathrm{mg} / \text { peny- } \\
\text { ajian) }\end{array}$} \\
\hline & Hilo & $\%$ & Anlene & $\%$ \\
\hline $1 \mathrm{x} /$ hari & 24 & 60,0 & 22 & 55,0 \\
\hline $2 \mathrm{x} /$ hari & 6 & 15,0 & 13 & 32,5 \\
\hline $3 \mathrm{x} /$ hari & 4 & 10,0 & 5 & 12,5 \\
\hline$>3 \mathrm{x} /$ hari & 6 & 15,0 & 0 & 0,0 \\
\hline Jumlah & 40 & 100 & 40 & 100 \\
\hline
\end{tabular}

\section{d. Lama Konsumsi}

Lama konsumsi suatu produk merupakan salah satu perilaku konsumen. Lama konsumsi bisa dijadikan indikator loyalitas konsumen terhadap suatu merek tertentu. Lamanya konsumen dalam mengkonsumsi suatu produk susu bubuk berkalsium tinggi bisa dilihat pada tabel berikut ini:
Tabel 5. Lama Konsumsi Susu Bubuk Berkalsium Tinggi

\begin{tabular}{lcrcr}
\hline $\begin{array}{c}\text { Lama Kon- } \\
\text { sumsi }\end{array}$ & Hilo & \multicolumn{1}{c}{ Merek Susu } \\
\hline 0-3 bulan & 19 & 47,5 & 8 & 20,0 \\
3-6 bulan & 12 & 30,0 & 8 & 20,0 \\
6-9 bulan & 2 & 5,0 & 7 & 17,5 \\
9-12 bulan & 2 & 5,0 & 3 & 7,5 \\
> 12 bulan & 5 & 12,5 & 14 & 35,0 \\
\hline \multicolumn{1}{c}{ Jumlah } & 40 & 100 & 40 & 100
\end{tabular}

Sumber: Data Primer (diolah)

\section{Kepuasan Konsumen}

Atribut merek, rasa, label, harga, dan promosi memberikan pengaruh kepuasan konsumen terhadap suatu produk (Chasanah, 2010). Hasil penelitian membuktikan bahwa terdapat korelasi antara atribut-atribut susu bubuk berkalsium tinggi dengan kepuasan konsumen. Hubungan korelasi tersebut yaitu:

Tabel 6. Korelasi Kepuasan terhadap Atribut

\begin{tabular}{|c|c|c|}
\hline Atribut & $\begin{array}{c}\text { Nilai Ko- } \\
\text { relasi }\end{array}$ & Keterangan \\
\hline \multicolumn{3}{|l|}{ Anlene } \\
\hline merek & 0,302 & tidak signifikan \\
\hline rasa & 0,001 & signifikan \\
\hline label & 0,417 & tidak signifikan \\
\hline harga & 0,018 & signifikan \\
\hline promosi & 0,023 & signifikan \\
\hline \multicolumn{3}{|l|}{ Hilo } \\
\hline merek & 0,024 & signifikan \\
\hline rasa & 0,137 & tidak signifikan \\
\hline label & 0,015 & signifikan \\
\hline harga & 0,385 & tidak signifikan \\
\hline promosi & 0,289 & tidak signifikan \\
\hline
\end{tabular}

Korelasi kepuasan konsumen terhadap atribut-atribut susu bubuk Anlene yang mempunyai nilai signifikan yaitu rasa, harga, dan promosi, sedangkan merek dan label tidak signifikan. Menurut Amam (2015) sikap konsumen terhadap atribut susu bubuk Anlene mempunyai nilai positif yaitu sebesar 4,73 , dan dari atribut yang mempunyai nilai positif paling tinggi yaitu harga sebesar 1,36, dan itu telah dibuktikan dengan tingkat kepuasan konsumen terhadap atribut susu bubuk berkalsium tinggi. 
Tingkat kepuasan konsumen yang dihasilkan dari atribut merek, rasa, label, harga, dan promosi susu bubuk Anlene yaitu sebesar (R2) $21,3 \%$, dan sisanya bisa dipengaruhi oleh sebab-sebab yang lain. Ibrahim (2001) menjelaskan bahwa banyak faktor yang mempengaruhi kepuasan pelanggan, yaitu diantaranya pelayanan, atribut kemasan produk, dan atribut penampilan produk.

Koefisien tingkat kepuasan konsumen terhadap atribut-atribut susu bubuk Anlene yaitu dapat digambarkan dalam persamaan sebagai berikut:

$$
\begin{array}{ll}
\mathrm{Y} & =1,781+0,165 \mathrm{X}_{1}+0,481 \mathrm{X}_{2}+0,024 \mathrm{X}_{3}+ \\
& 0,056 \mathrm{X}_{4}+0,121 \mathrm{X}_{5}
\end{array}
$$

Korelasi kepuasan konsumen terhadap atribut-atribut susu bubuk Hilo yang mempunyai nilai signifikan yaitu merek dan label, sedangkan rasa, harga, dan promosi tidak signifikan. Menurut Amam (2015) sikap konsumen terhadap atribut susu bubuk Hilo mempunyai nilai positif yaitu sebesar 4,93, dan dari atribut yang mempunyai nilai atribut paling tinggi yaitu merek sebesar 1,13, dan itu telah dibuktikan dengan tingkat kepuasan konsumen terhadap atribut susu bubuk berkalsium tinggi.

Tingkat kepuasan konsumen yang dihasilkan dari atribut merek, rasa, label, harga, dan promosi susu bubuk Hilo yaitu sebesar (R2) 26,7\%, dan sisanya bisa dipengaruhi oleh sebab-sebab yang lain. Hidayat (2008) menjelaskan bahwa banyak faktor yang mempengaruhi kepuasan pelanggan, yaitu diantaranya keterjangkauan produk, ketersediaan barang, dan kualitas produk.

Koefisien tingkat kepuasan konsumen terhadap atribut-atribut susu bubuk Hilo yaitu dapat digambarkan dalam persamaan sebagai berikut:

$$
\begin{aligned}
& \mathrm{Y}=3,14+0,309 \mathrm{X}_{1}+0,177 \mathrm{X}_{2}+0,213 \mathrm{X}_{3}+ \\
& \quad 0,048 \mathrm{X}_{4}+0,091 \mathrm{X}_{5}
\end{aligned}
$$

\section{Loyalitas Konsumen}

Atribut merek, rasa, label, harga, dan promosi memberikan pengaruh kepuasan konsumen terhadap suatu produk (Pratama, Susanta dan Suryoko, 2013). Hasil penelitian membuktikan bahwa terdapat korelasi antara atribut-atribut susu bubuk berkalsium tinggi dengan kepuasan konsumen. Hubungan korelasi tersebut yaitu:
Tabel 7. Korelasi Loyalitas terhadap Atribut

\begin{tabular}{lcc}
\hline \multicolumn{1}{c}{ Atribut } & $\begin{array}{c}\text { Nilai Ko- } \\
\text { relasi }\end{array}$ & Keterangan \\
\hline Anlene & & \\
merek & 0,207 & tidak signifikan \\
rasa & 0,226 & tidak signifikan \\
label & 0,417 & tidak signifikan \\
harga & 0,017 & signifikan \\
promosi & 0,129 & tidak signifikan \\
\cline { 1 - 1 } Hilo & & \\
merek & 0,021 & signifikan \\
rasa & 0,211 & tidak signifikan \\
label & 0,129 & tidak signifikan \\
harga & 0,245 & tidak signifikan \\
promosi & 0,314 & tidak signifikan \\
\hline & & Sig. 0,025
\end{tabular}

Korelasi loyalitas konsumen terhadap atribut-atribut susu bubuk Anlene yang mempunyai nilai signifikan yaitu hanya harga, sedangkan yang lainnya yaitu merek, rasa, label, dan promosi tidak signifikan. Menurut Amam (2015) sikap konsumen terhadap atribut susu bubuk Anlene mempunyai nilai positif yaitu sebesar 4,73 , dan dari atribut yang mempunyai nilai positif paling tinggi yaitu harga sebesar 1,36, dan itu telah dibuktikan dengan tingkat kepuasan konsumen terhadap atribut susu bubuk berkalsium tinggi.

Tingkat kepuasan konsumen yang dihasilkan dari atribut merek, rasa, label, harga, dan promosi susu bubuk Anlene yaitu sebesar (R2) $19,7 \%$, dan sisanya bisa dipengaruhi oleh sebab-sebab yang lain. Ibrahim (2001) menjelaskan bahwa banyak faktor yang mempengaruhi kepuasan pelanggan, yaitu diantaranya pelayanan, atribut kemasan produk, dan atribut penampilan produk.

Koefisien tingkat kepuasan konsumen terhadap atribut-atribut susu bubuk Anlene yaitu dapat digambarkan dalam persamaan sebagai berikut:

$$
\begin{aligned}
& \mathrm{Y}=3,220+0,142 \mathrm{X}_{1}+0,044 \mathrm{X}_{2}+0,002 \mathrm{X}_{3}+ \\
& 0,330 \mathrm{X}_{4}+0,220 \mathrm{X}_{5}
\end{aligned}
$$

Korelasi kepuasan konsumen terhadap atribut-atribut susu bubuk Hilo yang mempunyai nilai signifikan yaitu hanya merek, sedangkan atribut yang lain yaitu rasa, label, harga, dan pro- 
mosi tidak signifikan. Menurut Amam (2015) sikap konsumen terhadap atribut susu bubuk Hilo mempunyai nilai positif yaitu sebesar 4,93, dan dari atribut yang mempunyai nilai atribut paling tinggi yaitu merek sebesar 1,13 , dan itu telah dibuktikan dengan tingkat kepuasan konsumen terhadap atribut susu bubuk berkalsium tinggi.

Tingkat kepuasan konsumen yang dihasilkan dari atribut merek, rasa, label, harga, dan promosi susu bubuk Hilo yaitu sebesar $\left(\mathrm{R}^{2}\right) 21,3 \%$, dan sisanya bisa dipengaruhi oleh sebab-sebab yang lain. Hidayat (2008) menjelaskan bahwa banyak faktor yang mempengaruhi kepuasan pelanggan, yaitu diantaranya keterjangkauan produk, ketersediaan barang, dan kualitas produk.

Koefisien tingkat kepuasan konsumen terhadap atribut-atribut susu bubuk Hilo yaitu dapat digambarkan dalam persamaan sebagai berikut:

$$
\begin{aligned}
& \mathrm{Y}=0,480+0,038 \mathrm{X}_{1}+0,043 \mathrm{X}_{2}+0,032 \mathrm{X}_{3}+ \\
& \quad 0,322 \mathrm{X}_{4}+0,466 \mathrm{X}_{5} .
\end{aligned}
$$

\section{KESIMPULAN}

Berdasarkan hasil pembahasan, maka dapat diambil beberapa kesimpulan antara lain sebagai berikut:

1. Atribut rasa, harga, dan promosi yang dimiliki oleh susu bubuk Anlene mempengaruhi tingkat kepuasan konsumen, sedangkan yang mempengaruhi kepuasan konsumen susu bubuk Hilo ialah atribut merek dan label.

2. Loyalitas konsumen pada susu bubuk Anlene dipengaruhi oleh atribut harga, sedangkan loyalitas konsumen pada susu bubuk Hilo dipengaruhi oleh atribut merek.

\section{DAFTAR PUSTAKA}

Amam. 2015. Analisis Sikap Konsumen terhadap Susu Bubuk Berkalsium Tinggi dengan Menggunakan Multi-Atribut Model dan Norma Subyektif Model. Jurnal Wacana 19 (1) 1-12.

Amam dan Pradiptya, A. H. 2017. Analysis of Fishbein on a Multi-attribute Model Approach to Determine the Attitude of Coffee Consumers in Jember District. Jember International Coffee Conferences. Lembaga Penelitian dan Pengabdian Masyarakat. Universitas Jember.

Astriyendy, R. D. 2006. Pengaruh Atribut Pro- duk terhadap Keputusan Pembelian Anlene Rendah Laktosa pada PT Fonterra Brands Indonesia Cabang Bandung. Jurnal Fakultas Ilmu Sosial dan Politik. Universitas Pasundan.

Chasanah, N. 2010. Analisis Perilaku Konsumen dalam Membeli Produk Susu Instan di Pasar Modern. Jurnal Fakultas Pertanian Universitas Sebelas Maret.

Engel, F., James, R., Blackwell, D., Paul, W., Miniard. Consumer Behaviour $8^{\text {th }}$ Edition. 2001. Dryden Press. Hourcout Brace Collage Publisher.

Hidayat, S. I. 2008. Penilaian Konsumen terhadap Beberappa Atribut Dua Jenis Rokok Produk Sampoerna. Jurnal Riset Ekonomi dan Bisnis 8 (2) 1-10.

Ibrahim. 2001. Analisis Sikap Konsumen Terhadap Atribut Sabun Mandi Biasa di Kota Yogyakarta: Studi Kasus Sabun Mandi Merek Lux dan Giv. Jurnal Ilmu Manajemen. Manajemen Pemasaran. UB. Malang.

Istiana, L., Syahlani, S.P., dan Nurtini, S. 2006. Pengaruh Sikap, Norma Subyektif \& Kontrol Keperilakuan Terhadap Niat \& Perilaku beli Produk Susu UHT. Jurnal Ilmiah - Ilmu Peternakan, UGM. Yogyakarta.

Kottler, P. 2000. Manajemen Pemasaran: Analisis, Perencanaan, Implementasi \& Kontrol. Edisi IX. Prenhallindo. Jakarta.

Ningrum, N. P. 2010. Analisa Pengaruh Label Nutrisi terhadap Minat Beli Produk Susu Rendah Lemak dan Tinggi Kalsium Merek Produgen di Surabaya. Jurnal Fakultas Ekonomi. Universitas Pembangunan Nasional Veteran.

Pratama, D. P., Susanta, H., dan Suryoko, S. 2013. Pengaruh Threat Emotions, kepercayaan Merek, dan Harga terhadap Keputusan Pembelian Produk Susu Anlene Actifit. Diponegoro Journal of Social and Politic. 1-10. 
Rahmawati, V. 2013. Pengaruh Atribut Produk sebagai Variabel Moderating terhadap Keputusan Pembelian Produk Kosmetik Wardah di Kota Semarang. Jurnal Fakultas Ekonomi dan Bisnis Universitas Dian Nuswantoro.

Sanusi, A. 2012. Metodologi Penelitian Bisnis. Edisi kedua. Penerbit: Salemba Empat. Jakarta.

Sihombing, S. S. dan Situmorang, S. H. 2014. Pengaruh Harga, Kemasan, dan Iklan terhadap Keputusan Pembelian Minute Maid Pulpy Orange pada Siswa SMA Negeri 1 Medan. Jurnal Manajemen Fakultas Ekonomi Sumatera Utara. 